\title{
Pharmacologic Pain Management in Outpatient Uterine Fibroid Embolization
}

\begin{abstract}
The key for successful uterine fibroid embolization in outpatient setting is good management of pain and other postembolization symptoms. Although several different protocols with different medication regimens have been used successfully in multiple institutions, it is still a challenge for interventional radiologists who should be prepared to provide detailed follow-up plans, continuous staff availability, and an oral medication regimen sufficient to alleviate these symptoms. Moreover, the interventional radiologist should be able to educate the patient about this postprocedural pain and available treatments.
\end{abstract}

Keywords: Outpatient setting, pain, uterine fibroid embolization

\section{Introduction}

Uterine fibroid embolization (UFE) is an effective treatment for symptomatic uterine fibroid and an alternative to traditional surgical therapies. It successfully controls symptoms in $85 \%-95 \%$ of patients for a median of 24 months..$^{[1-4]}$ It was recognized and listed by the American College of Obstetricians and Gynecologists in the Level A treatment category in the management of uterine fibroids as a safe and effective treatment option based on long- and short-term outcomes. ${ }^{[5]}$

UFE is accomplished with bilateral occlusion of the uterine artery, with the end point being stasis or near stasis in the artery and with no large uterine artery branches remaining patent. As the fibroid tissue is more vulnerable to embolization than the myometrium, UFE will result in irreversible ischemia and complete infarction of fibroids with gradual reversible ischemia of myometrium. ${ }^{[6,7]}$ These myometrial ischemic changes most likely cause significant pelvic pain with variable degrees of intensity within the first $24 \mathrm{~h}$. Although such pain should not be considered a complication of UFE but an expected aspect of recovery, ${ }^{[6]}$ it continues to be a challenge for interventional radiologists to treat especially in outpatient setting of

This is an open access journal, and articles are distributed under the terms of the Creative Commons AttributionNonCommercial-ShareAlike 4.0 License, which allows others to remix, tweak, and build upon the work non-commercially, as long as appropriate credit is given and the new creations are licensed under the identical terms.

For reprints contact: reprints@medknow.com
UFE as it is the most common reason for readmission. ${ }^{[8]}$

\section{Pain after Uterine Fibroid \\ Embolization}

Post-UFE pain is both variable and unpredictable. It is most commonly described as menstrual-type cramps within the first $24 \mathrm{~h}$ after the procedure. Although there is little or no pain during the procedure, the pain starts when embolization is completed. It peaks at $7 \mathrm{~h}$ after the procedure and it starts to improve gradually over time. ${ }^{[9]}$ Its intensity is variable and ranges from mild cramps to cramps comparable with childbirth. ${ }^{[10]}$ Interpatient variations occur, ${ }^{[11]}$ and pain degree and experience are unpredictable in general as they are unrelated to the patient age, fibroid size and location, uterine size, and has no significant association with the size of embolic material used. ${ }^{[9,12]}$ However, the use of a large volume of embolic agents is associated with severe post-UFE pain, ${ }^{[13]}$ while limited or incomplete embolization with polyvinyl alcohol particles or gelatin-coated tris-acryl polymer microspheres may produce significant effective infarction of fibroids with less severe pain. ${ }^{[14]}$

Racial difference in pain perception levels has been noted as a sole predictive factor prior to UFE as Black women recorded greater pain than White women. ${ }^{[9,15]}$ However, White women who had a greater

How to cite this article: Khankan AA, Al-Habli IA, Alhazmi T, Feteih I, Valenti DA. Pharmacologic pain management in outpatient uterine fibroid embolization. Arab J Intervent Radiol 2018;2:50-5.
Azzam A. Khankan, Ibrahim A. Al-Habli, Turki Alhazmi', lyad Feteih², David A. Valenti ${ }^{3}$

Department of Medical Imaging, King Abdulaziz Medical City, Jeddah,

${ }^{1}$ Department of Radiology, Umm Al-Qura University, Makkah, ${ }^{2}$ Department of Radiology, King Fahd

Hospital, Jeddah, Saudi Arabia ${ }^{3}$ Department of Diagnostic Radiology, McGill University Health Center, Montreal, Canada

Address for correspondence: Dr. Azzam A Khankan, Department of Medical Imaging, King Abdulaziz Medical City, P.O. Box. 9515, Jeddah 214 23, Saudi Arabia. E-mail:khankana@ngha.med.sa

Access this article online

Website: www.arabjir.com

DOI: 10.4103/AJIR.AJIR_27_18 Quick Response Code:

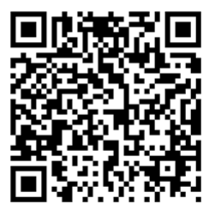


mean volume of dominant fibroid in the reported studies are more likely to have severe nausea and emesis associated with pain than Black women.

Pain and other postembolization symptom management is the clinical challenge to perform UFE as an outpatient procedure. ${ }^{[16]}$ It is the responsibility of the interventional radiologist to manage the symptoms experienced by these patients immediately after embolization.

\section{McGill University Health Center Protocol}

At our institution, McGill University Health Center, we use a simplified protocol for pain management after UFE [Table 1]. The protocol was designed and assessed in close cooperation with the departments of anesthesiology and gynecology. It includes acetaminophen, codeine, and nonsteroidal anti-inflammatory drugs naproxen in addition to mepiridine and fentanyl, when necessary. Based on a previous study by Pisco et $a l^{[17]}$, we started medications the night before and the day of the procedure to reduce the severity of postembolization symptoms, especially in regards to pain. After the procedure, the patient is transferred to the recovery room and aggressive treatment of pain is started until achieving the desired level of pain control. Pain is assessed on a regular basis to enable the administration of analgesics before progression to a level

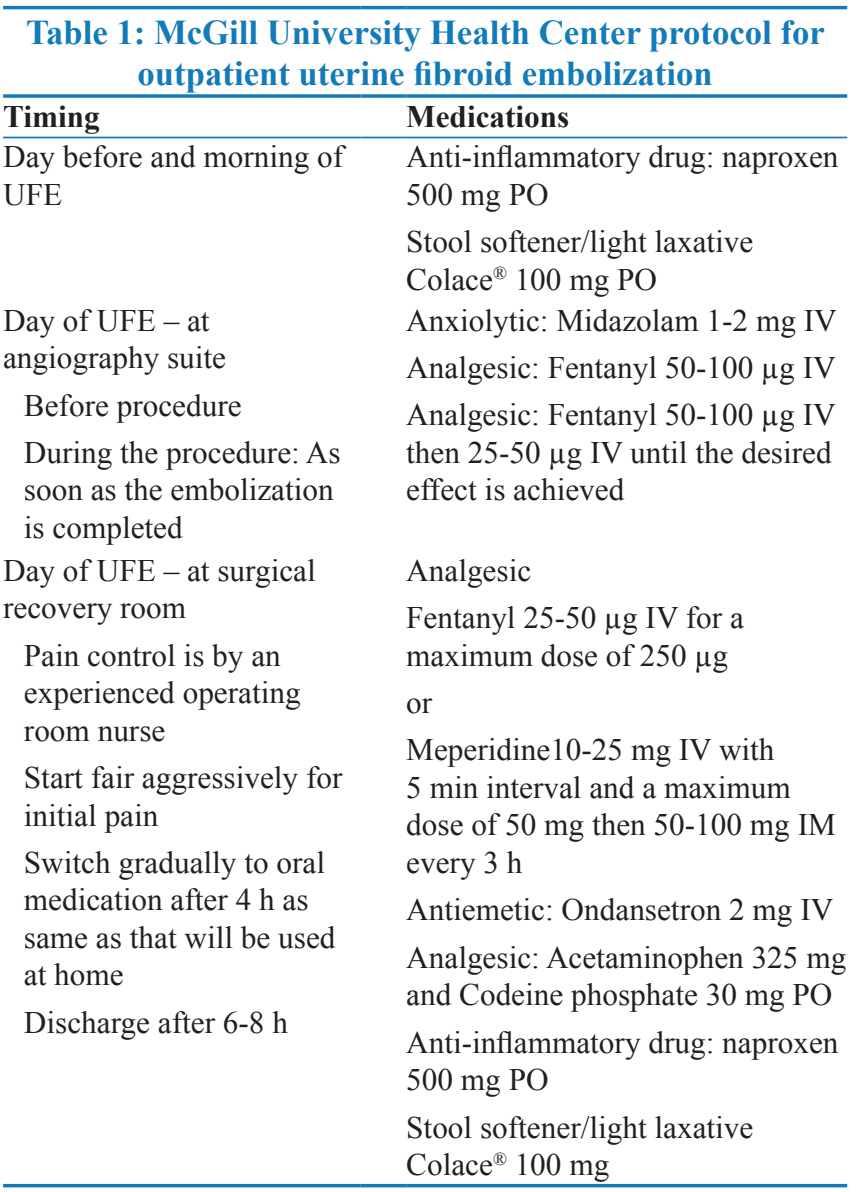

where pain control is virtually impossible. Switching to oral medication starts usually after $4 \mathrm{~h}$. We believe that oral medication if works in hospital, will work at home. The patient will be discharged home after 6-8 $\mathrm{h}$ and given appropriate instructions. In general, patients are recommended to take 1 week off from work. All patients are given appropriate contact numbers for the interventional radiology service, should any problems arise, and informed to return to the emergency department in case of severe pelvic pain which is unresponsive to the treatment. Patient follow-up consists of initial telephone contact during the first few days after UFE and a clinic visit at a 3- to 4-month interval. A magnetic resonance imaging scan is obtained at the 3-month follow-up visit. Nearly $81 \%$ of patients are discharged on the day of procedure and $19 \%$ of patients are admitted for pain control and/or fever control. ${ }^{[16]}$

\section{Reported Protocols}

Although a fixed pain medication protocol cannot be recommended, ${ }^{[15]}$ several different protocols with different medication regimens have been published in the literatures. ${ }^{[18-22]}$ They have been used attempting to control the pain and manage the nausea and vomiting associated with UFE in outpatient setting. No consensus regarding the best pain management method after UFE has been achieved, ${ }^{[23]}$ and most of the protocols use a combination of opioid analgesics and nonsteroidal anti-inflammatory drugs to control post-UFE pain in addition to antiemetics for the associated nausea.

In addition, the use of superior hypogastric nerve block may significantly reduce pain and the need for narcotics. ${ }^{[24]}$

The reported medication protocols in outpatient UFE are summarized in Table 2.

\section{Patient Education}

Most UFE patients are otherwise well and are able to communicate their experience and needs regarding pain and other symptoms. To achieve such needs, it is important to inform the patients during the initial consultation and on the morning of the procedure about the expected symptoms during the post-UFE recovery period and the medication regimen that will be used to manage these symptoms, especially the pain and vomiting. Moreover, the patient must receive a written form about all these symptoms with clear instructions regarding the adjustment in their medications, especially those prescribed for pain.

In summary, post-UFE pain in outpatient setting poses unique challenges to the interventional radiologists, who must be fully knowledgeable of the available methods and medications to provide safe and reliable pain relief, tailored for each individual patient. Both the education of patients regarding expected symptoms and the interventionalists' experience with a spectrum of medications in each 


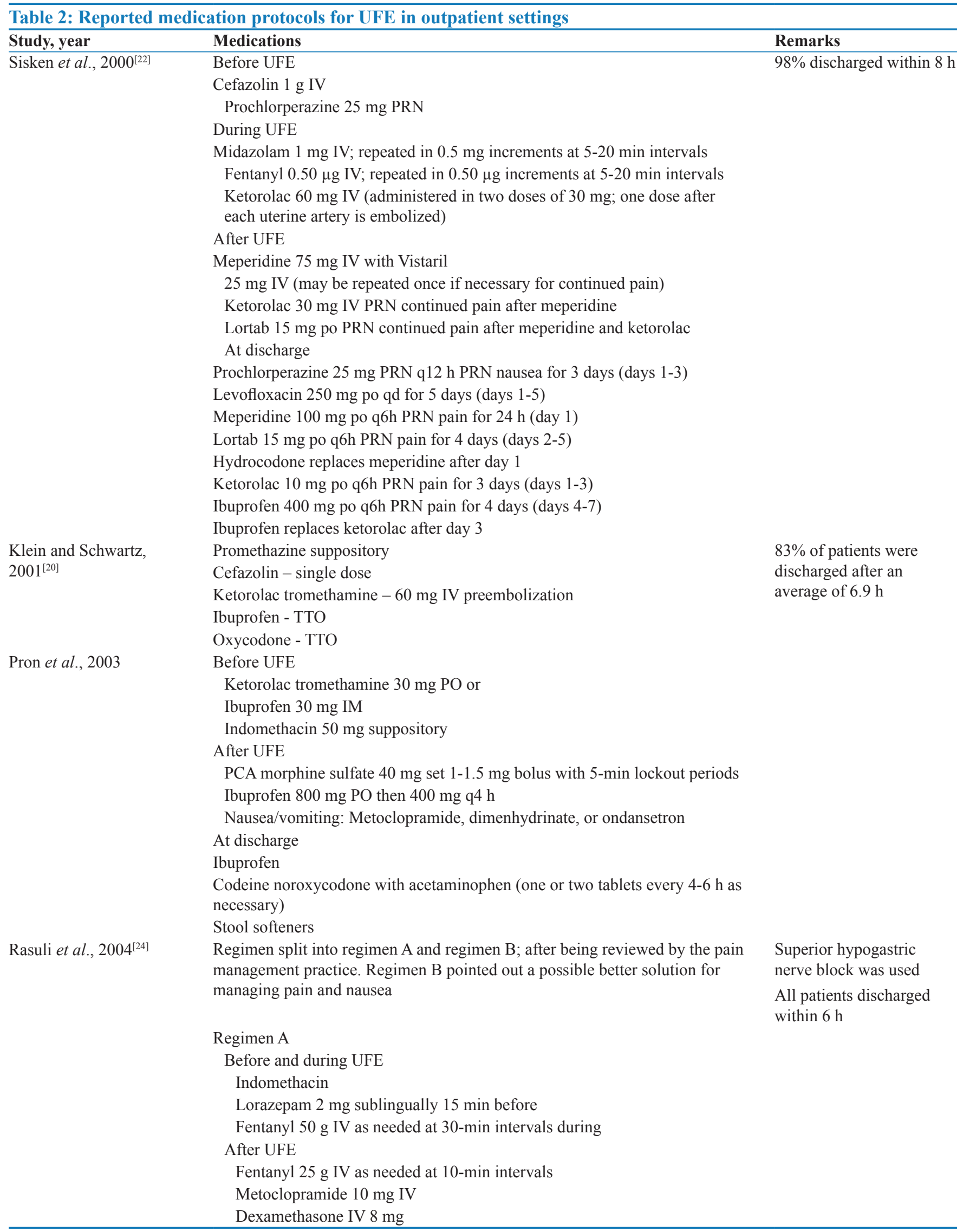


Table 2: Contd...

Study, year

Baerlocher et al., 2006 $6^{[19]}$

Pisco et al., 2009 21$]$

Medications

At discharge

Morphine $10 \mathrm{mg}$ orally every $4 \mathrm{~h}$ as needed for 7 days

Metoclopramide $10 \mathrm{mg}$ orally daily as needed for nausea

Indomethacin $100 \mathrm{mg}$ rectal suppository every $12 \mathrm{~h}$

Ciprofloxacin $500 \mathrm{mg}$ orally daily

Note - IV intravenous

Regimen B

Before and during UFE

Naprosyn $500 \mathrm{mg}$ rectal suppository before UFE

Morphine 5-10 mg IV during UFE

Midazolam 1-2 mg IV during UFE

Cefazolin $1 \mathrm{~g}$ IV before UFE

After UFE

Long-acting morphine $30 \mathrm{mg}$ orally

Morphine $2 \mathrm{mg}$ IV PRN at hourly intervals

Dimenhydrinate $50 \mathrm{mg}$ IV

Dexamethasone $8 \mathrm{mg}$ IV

Prochlorperazine $10 \mathrm{mg}$ rectal suppository PRN for nausea

At discharge

Long-acting morphine $30 \mathrm{mg}$ PRN $12 \mathrm{~h}$ for 7 days

Morphine $10 \mathrm{mg}$ orally $\mathrm{q} 4 \mathrm{~h}$ as needed for 4 days

Dimenhydrinate $50 \mathrm{mg}$ rectal suppository daily for 7 days

Naprosyn $500 \mathrm{mg}$ rectal suppository daily for 7 days

Ciprofloxacin $500 \mathrm{mg}$ orally daily for 7 days

Before UFE

IV two-thirds 5\% dextrose, one-third $0.9 \%$ normal saline at $150 \mathrm{cc} / \mathrm{h}$

Cefazolin $1 \mathrm{~g}$ IV or vancomycin $500 \mathrm{mg}$

Metoclopramide $10 \mathrm{mg}$ IV

Ketorolac $30 \mathrm{mg}$ IV

Ondansetron $16 \mathrm{mg}$ orally

After UFE

IV two-thirds $5 \%$ dextrose, one-third $0.9 \%$ normal saline at $150 \mathrm{cc} / \mathrm{h}$

Morphine 2-4 mg IV every $5 \mathrm{~min}$ as needed

Gravol 25-50 mg IV every $4 \mathrm{~h}$ as needed

Oxycodone $10 \mathrm{mg}$ orally $4 \mathrm{~h}$ postprocedure

Day before UFE

Omeprazole $20 \mathrm{mg}$ by mouth

Naproxen $1000 \mathrm{mg}$ by mouth

Hydroxyzine $25 \mathrm{mg}$ by mouth

Stool softener suppositories

Day of UFE

Diazepam $5 \mathrm{mg}$ sublingually

Omeprazole $20 \mathrm{mg}$ IV

Metamizole $2 \mathrm{~g}$ IV

Tramadol $100 \mathrm{mg}$ IV

Metoclopramide $25 \mathrm{mg}$ IV

Droperidol 0.10 mg IV

Piroxicam $20 \mathrm{mg}$ IV

Cefazolin $1 \mathrm{~g}$ IV

During UFE

Ketorolac $30 \mathrm{mg}$ IV $\times 2$

Midazolam $1 \mathrm{mg}$ IV if needed

After UFE
Morphine was used through a controlled analgesic pump

Most of patients discharged 6-10 $\mathrm{h}$ after UFE 


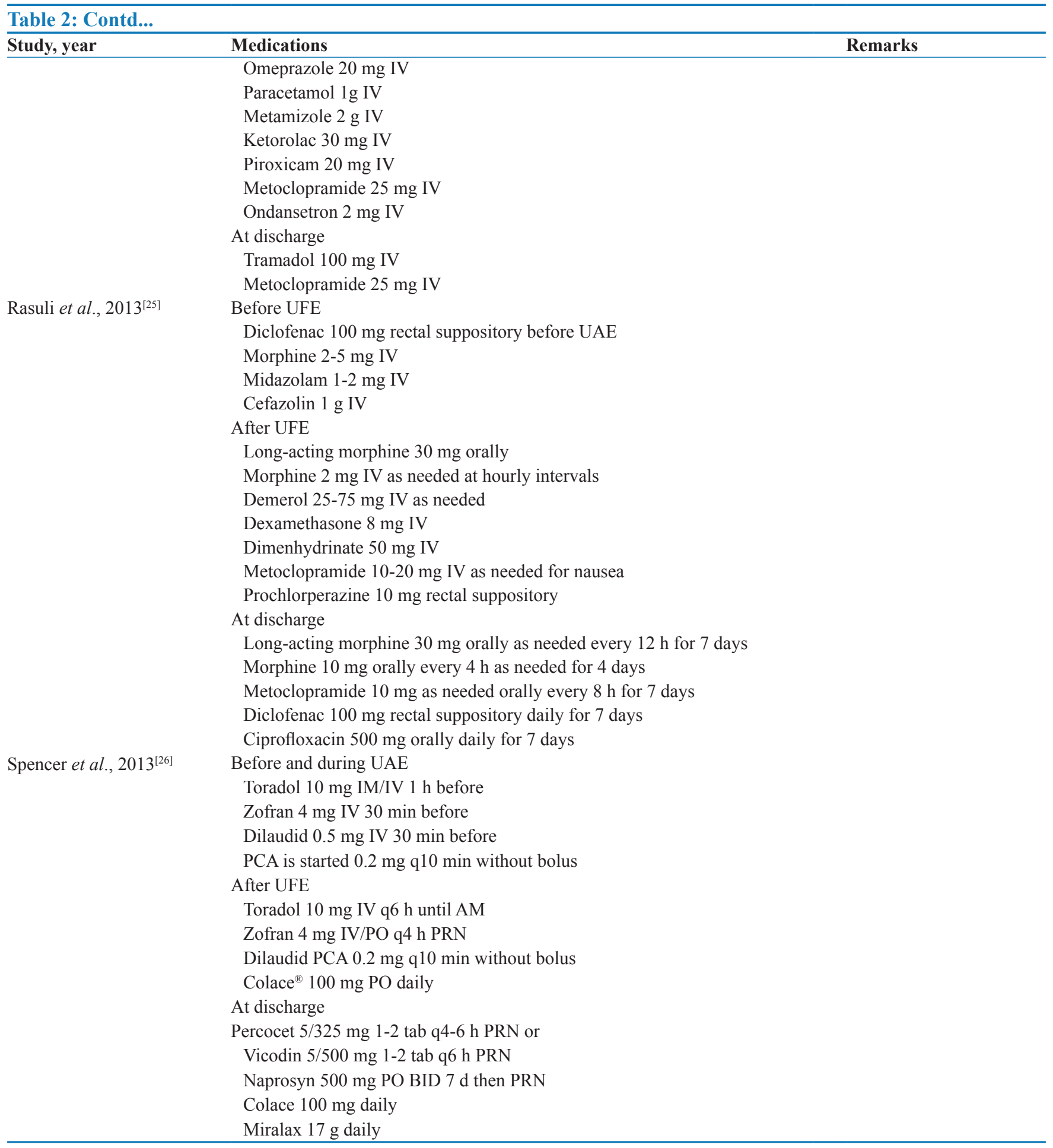

PCA: Patient-controlled analgesia

category prove helpful in optimizing each patient's care and achieving individual satisfactions.

Financial support and sponsorship

Nil.

\section{Conflicts of interest}

There are no conflicts of interest.

\section{References}

1. Marret H, Alonso AM, Cottier JP, Tranquart F, Herbreteau D, Body G, et al. Leiomyoma recurrence after uterine artery embolization. J Vasc Interv Radiol 2003;14:1395-9.

2. Ravina JH, Aymard A, Ciraru-Vigneron N, Clerissi J, Merland JJ. Uterine fibroids embolization: Results about 454 cases. Gynecol Obstet Fertil 2003;31:597-605.

3. Spies JB, Ascher SA, Roth AR, Kim J, Levy EB, Gomez-Jorge J, 
et al. Uterine artery embolization for leiomyomata. Obstet Gynecol 2001;98:29-34.

4. Walker WJ, Pelage JP. Uterine artery embolisation for symptomatic fibroids: Clinical results in 400 women with imaging follow up. BJOG 2002;109:1262-72.

5. American College of Obstetricians and Gynecologists. ACOG practice bulletin. Alternatives to hysterectomy in the management of leiomyomas. Obstet Gynecol 2008;112:387-400.

6. Hovsepian DM, Siskin GP, Bonn J, Cardella JF, Clark TW, Lampmann LE, et al. Quality improvement guidelines for uterine artery embolization for symptomatic leiomyomata. J Vasc Interv Radiol 2004;15:535-41.

7. Ruuskanen A, Sipola $P$, Hippeläinen $M$, Wüstefeld $M$, Manninen H. Pain after uterine fibroid embolisation is associated with the severity of myometrial ischaemia on magnetic resonance imaging. Eur Radiol 2009;19:2977-85.

8. Walker WJ, Pelage JP, Sutton C. Fibroid embolization. Clin Radiol 2002;57:325-31.

9. Kim HS, Czuczman GJ, Nicholson WK, Pham LD, Richman JM. Pain levels within 24 hours after UFE: A comparison of morphine and fentanyl patient-controlled analgesia. Cardiovasc Intervent Radiol 2008;31:1100-7.

10. Siskin GP, Bonn J, Worthington-Kirsch RL, Smith SJ, Shlansky-Goldberg R, Machan LS, et al. III. Uterine fibroid embolization: Pain management. Tech Vasc Interv Radiol 2002;5:35-43.

11. Carr DB, Goudas LC. Acute pain. Lancet 1999;353:2051-8.

12. Roth AR, Spies JB, Walsh SM, Wood BJ, Gomez-Jorge J, Levy EB, et al. Pain after uterine artery embolization for leiomyomata: Can its severity be predicted and does severity predict outcome? J Vasc Interv Radiol 2000;11:1047-52.

13. Volkers NA, Hehenkamp WJ, Birnie E, de Vries C, Holt C, Ankum WM, et al. Uterine artery embolization in the treatment of symptomatic uterine fibroid tumors (EMMY trial): Periprocedural results and complications. J Vasc Interv Radiol 2006;17:471-80.

14. Spies JB. Recovery after uterine artery embolization: Understanding and managing short-term outcomes. J Vasc Interv Radiol 2003;14:1219-22.

15. Hehenkamp WJ, Volkers NA, Birnie E, Reekers JA, Ankum WM. Pain and return to daily activities after uterine artery embolization and hysterectomy in the treatment of symptomatic uterine fibroids: Results from the randomized EMMY trial. Cardiovasc Intervent Radiol 2006;29:179-87.

16. Al-Fozan H, Dufort J, Kaplow M, Valenti D, Tulandi T. Cost analysis of myomectomy, hysterectomy, and uterine artery embolization. Am J Obstet Gynecol 2002;187:1401-4.

17. Pisco J. How to reduce the severity of pain after uterine artery embolization of fibroid for leiomyomata. Cardiovascular and Interventional Radiological Society of Europe Annual Scientific and Postgraduate Educational Meeting 8-12 September, 2007. Athens, Greece: Springer; 2007. p. S317.

18. Goodwin SC, Walker WJ. Uterine artery embolization for the treatment of uterine fibroids. Curr Opin Obstet Gynecol 1998; 10:315-20.

19. Baerlocher MO, Asch MR, Hayeems EB, Rajan DK. Uterine artery embolization - Inpatient and outpatient therapy: A comparison of cost, safety, and patient satisfaction. Can Assoc Radiol J 2006;57:95-105.

20. Klein A, Schwartz ML. Uterine artery embolization for the treatment of uterine fibroids: An outpatient procedure. Am J Obstet Gynecol 2001;184:1556-60.

21. Pisco JM, Bilhim T, Duarte M, Santos D. Management of uterine artery embolization for fibroids as an outpatient procedure. J Vasc Interv Radiol 2009;20:730-5.

22. Siskin GP, Stainken BF, Dowling K, Meo P, Ahn J, Dolen EG, et al. Outpatient uterine artery embolization for symptomatic uterine fibroids: Experience in 49 patients. J Vasc Interv Radiol 2000;11:305-11.

23. Andrews RT, Spies JB, Sacks D, Worthington-Kirsch RL, Niedzwiecki GA, Marx MV, et al. Patient care and uterine artery embolization for leiomyomata. J Vasc Interv Radiol 2004; $15: 115-20$.

24. Rasuli P, Jolly EE, Hammond I, French GJ, Preston R, Goulet S, et al. Superior hypogastric nerve block for pain control in outpatient uterine artery embolization. J Vasc Interv Radiol 2004;15:1423-9.

25. Rasuli P, Sabri A, Hammond I, French GJ, Gamache N, Jolly EE, et al. Outpatient uterine artery embolization for symptomatic fibroids: Short- and long-term single institution-based outcomes. J Obstet Gynaecol Can 2013;35:156-63.

26. Spencer EB, Stratil P, Mizones H. Clinical and periprocedural pain management for uterine artery embolization. Semin Intervent Radiol 2013;30:354-63. 